\title{
Reform of Physical Education Teaching and Cultivation of Life - long Sports Consciousness in Higher Vocational Colleges
}

\author{
Palihati • Dawuti \\ Department of Sports,Xinjiang Teacher' s College, Urumqi,:830043, \\ China
}

\begin{abstract}
With the continuous development of the times, competition among talents has become ever more intense. How to develop close to the needs of the community with a variety of talents, it becomes very important. In this case, we can only college sports education and lifelong sports education combined, can be achieved. Through the clarification and exposition of the relationship between the two, we can identify students in the important stage of life foundation, continue to learn, the school must cultivate professional students of lifelong physical education awareness, in order to promote higher education In the reform of physical education.

Keywords Vocational education Physical education Lifelong consciousness
\end{abstract}

\section{Introduction}

As society moves forward, the competition among talents becomes more and more intense. Therefore, how to cultivate talents should be put forward and teachers should put forward higher demands on teaching. In order to enable students to adapt to the increasingly modern technology, school education should be more universal, school education in the 21 st century to continue to increase their own physical education reform. The State Council of the CPC Central Committee and State Council on the "deepening of the educational reform to promote quality education in a comprehensive decision" pointed out: healthy 
physique, young people for the motherland and the people serving the foundation and premise of the Chinese nation strong vitality. Therefore, in the school education to establish a vigorous first thought, effectively into the education work. So, the school physical education should be the way to improve the health of students? How to explore students with strong vitality? And develop a good habit of exercising the body, is the foundation for achieving goals. This model has become the top priority for achieving the goal of comprehensive development and reform.[1]

\section{The relationship between college physical education and lifelong education}

At the same time, the school bears the responsibility of promoting students 'health, strengthening students' physique, cultivating the moral quality, and also shoulder the task of physical education.University, physical education, physical education Only physical education in colleges and universities, the use of physical exercise in this way, to promote personal life in the course of the final stage of physical education. This is also the school physical education at the school level the highest level. During this period, students in the bodily development of the basic golden age. Regardless of their thinking or will be quality, have been basically to mature. Therefore, in such a critical period, students in general freedom of consciousness are very strong case, vocational colleges and specialized physical education are extremely important.

At this stage, the school physical education but also for students to continue with individual socialization of the shaping process. Students are very different, how different students for creative personality training, so that students gradually formed their own comparative advantages of sports, and like and good at sports is very important, the only way, in the physical education Lifelong aspects to give students a good foundation.[2]

Has been out of the school students after graduation, examination of higher vocational college sports educating effect of the important sign is that they continue to exercise fitness? Or stop physical exercise? Therefore, in the vocational college, training their specific sports habits is very important. This stage is to establish the concept of lifelong sports the most critical stage, but also

\section{The way to cultivate the sense of lifelong physical education for college students}

3.1. The development of the idea of Lifelong physical education, improve the school education system reform

Lifelong sports are a theory of cultivating students' habits of lifelong physical exercise. This theory holds that: the habit of life-long physical education in schools is the most important thing. This theory holds that in the school education 
stage to cultivate the goal of lifelong exercise habits of students at the basic, so that students master the basic methods of physical activity. From the ideological point of view, only lifelong sports can achieve the purpose of health first. Only to ensure the long-term interests of students. At the same time, this approach also emphasizes the cultivation of student habits, so that life-long education and lifelong sports links, and provide services for the lifelong sport. Therefore, the reform of physical education in colleges and universities only adhere to lifelong sports as the guiding ideology in order to achieve and complete the times of college sports requirements, follow the development trend of the times.

\subsection{To develop interest as the goal to set the new course content}

School physical education, to lay a solid foundation for the student life of life, which is in the school sports education reform one of the goals. At the same time, uninterrupted personality training of students, so that students can really choose their favorite, but also the most effective at sports. At the same time, it is also the fundamental period to enhance students 'sense of lifelong sports identity formation, which is the key to cultivate the students' sports consciousness and carry on lifelong sports. The formation of the law of sports, people become conscious individuals, continue to carry out sensible exercise, in order to endless in all aspects of the continuous development of their own. The motive and selfneed of this kind of self are the root of sports interest and the purpose and process of teaching. For example, students learn to shoot or other basic skills and routines of some sports, they can continue to exercise in their spare time. After graduation, they go to work, these basic skills to become their means of life for sports. However, how to carry out teaching in the limited teaching time? And should choose those beneficial to the students, and can improve their sports ability content? The author believes that teachers should adhere to the teaching of scientific content, and the acceptability of educating content selection as a ruler. In other words, in the course content selection, we must adhere to the peopleoriented, and remove the tough and dangerous projects. To select a continuation of the exercise load of smaller sports. Therefore, in the choice of teaching materials, teachers should be full of students' sports ability and reality. At the same time, according to the actual conditions of the school, as much as possible to open more interested students in the subject. Only in this way, students continue to choose according to their hobbies and expertise. To choose those suitable for their own, while their interest in the project to learn, in order to fully mobilize their enthusiasm to participate in physical exercise. At the same time, we should give full play to the status of students, so that students continue to experience the movement of happiness, and gradually improve their own sports awareness.

\subsection{The content of physical education curriculum should be set closer to the professional}

Higher vocational colleges and universities is different from ordinary colleges and universities. Its main goal is to train practical technical personnel. This requires that students of diverse professional bodies to distinguish the specific requirements are not the same. Combined with the characteristics of different professions, choose different teaching content is to enable students to maximize 
the ability to adapt to specialized, for example, in the vocational schools in the static professional, is more. Such as secretarial, computer and accounting professional characteristics of such a shared professional in the choice of sports content should be targeted, such as aerobics, boxing gymnastics and other content. Therefore, in specific physical education, it is necessary to reflect the project's fun, but also has a strong practical. These physical exercise are conducive to the students into the community to maintain high efficiency of labor, and constantly play self-physical and stable psychological quality. According to the characteristics of students chooses the learning project can fully mobilize their enthusiasm, which also achieved the basic stage of lifelong physical education.[3]

\subsection{Establish a new teaching model}

For a long time, in the teaching of physical education in higher vocational colleges, teachers follow one or several traditional methods of teaching physical education model, due to monotonous methods, not pay attention to individual differences in students, with hard to strengthen the teaching content Students, making the teaching effect is not high. Will only makes students have physical dislike psychology. Therefore, schools and teachers to establish a new teaching model, the establishment of vocational skills training course. As a result, in the teaching of physical education in higher vocational colleges, students are actively and effectively guided into PE teaching, which stimulates the interest of students and enhances the students' learning effect. Sports clubs are one of the forms for students to be involved in physical exercise. In order to attract students to exercise for a long time, it is a very useful way to set up extracurricular sports clubs. In recent years, many colleges and universities on the traditional teaching mode, have carried out reform. It has been demonstrated by practice that the diversification of teaching modes is the method that truly embodies the teaching method of human-oriented principle. Only fully mobilize the initiative of students in order to enable students to figure out what is the real joy of sports.

\subsection{Reform traditional teaching methods}

Only in a relaxed atmosphere, students can form the concept of lifelong physical education. On the basis of traditional teaching methods, we should continue to innovate, change the boring teaching methods before, and constantly add fresh teaching ideas and thoughts. In this way, to stimulate students interest in learning sports, and gradually allow students to feel the charm of sports, active participation in the organization of sports activities among teachers. Of course, physical education is not confined to the form of theoretical teaching, to conduct as much practice. Teachers in teaching practice, to continue to discover and solve problems. According to the diverse characteristics of students focus on teaching students in accordance with their aptitude, to inspire students self-confidence, to explore their potential.

\subsection{To establish and improve the evaluation system of student sports} assessment

The traditional examination-oriented education, only pay attention to the student's sports performance, this evaluation system, the students in order to achieve the standard and continue to practice mechanically, do not want to take the initiative 
in sports, seriously damaged their enthusiasm, so that students in a very Passive state.

Evaluation of students, students should first start with the ideological, to instill the concept of lifelong education students, and fully allow students to participate in a variety of sports activities. In the teaching part of physical education, we should pay attention to the physical and mental health of students and their potentials is constantly cultivated and inspired, teachers should encourage students to give students ideological guidance, concerned about the progress of students bit by bit.[4]

In the end of physical education or the need for evaluation, dynamic evaluation and summative evaluation should be combined. This is because the end of the evaluation to facilitate horizontal comparison, it is relatively intuitive ability to measure, generally used in sports basic performance assessment, this time, this summative evaluation is a more appropriate approach. The dynamic evaluation is the development of students, is the evaluation of the state of student learning and development, more apt for longitudinal comparison.

In this way, students continue developing their own personal health status files. After the stage evaluation, the physical education before and after the results were compared, in order to sum up, so the assessment of physical education should be diversified. The evaluation of students 'sports consciousness can be evaluated according to the students"s learning attitude, attendance and other classroom performance. At the same time, students of various periods of sports activities to compare, continue to sum up, are the continuous improvement of students.

As we all know, an essential means of quality education is in the extracurricular sports activities, plays a supplementary role in classroom teaching. Students in the classroom learning in addition to this routine learning, the pursuit of a higher level of spiritual pursuit, enjoy the sports activities to their own special interest, so that consciously participate in them, improve their enthusiastic participation in the initiative. But also through the organization of clubs or other sports institutions, so that students take the initiative to consciously participate in sports activities, and constantly enrich the content of extra-curricular sports activities in the movement will be able to learn their own needs, skills, and applied to real life .[5]

\section{Concluding remarks}

Higher vocational college physical education, and its lifelong sense of physical education are the development trend of modern sports reform. To carry out a lifelong sports foundation, is the school sports, the realization of the national fitness program also relies on this important means to achieve. Therefore, in higher vocational colleges, the goal of reform of physical education has always been to adhere to, in order to perform sports activities, in order to enhance student interest, as a starting point. At the same time, teachers should combine the characteristics of discrete professions, reasonable arrangements for course content, and constantly enhance the practicality. Establish a diversified teaching 
model, improve the applicable assessment system, build a rich atmosphere of sports activities, while continuing to improve student enthusiasm for sports. Over time, students into the community, still can consciously participate in extracurricular sports activities, enrich their individual sports and cultural life. In this way, promote their concept of life-long sport, sports become a necessity in life, as their life is indispensable to the wonderful years.

\section{References}

[1] Matthew D. Curtner-Smith,The Occupational Socialization of a First-Year Physical Education Teacher with a Teaching Orientation. Sport Education \& Society, 6(1),pp:81-105,2001 .

[2]Bali N, Souissi K,Comparative Study of Physical Education Students Teachers Style Interventions Teaching Styles Skill. Creative Education, 06(1),pp:100113,2015 .

[3]Meng H Y, John Wang Chee Keng, The effectiveness of an AutonomySupportive Teaching Structure in Physical Education. Ricyde Revista Internacional De Ciencias Del Deporte, 12(43),pp:5-28,2016.

[4]Chen W, Mason S, Hypnar A, et al, Association of Quality Physical Education Teaching with Students' Physical Fitness.. Journal of Sports Science \& Medicine, 15(2),pp:335-343,2016.

[5]Kneubil F B, Robilotta M R,Physics Teaching: Mathematics as an Epistemological Tool. Science \& Education, 24(5),pp:1-16,2015. 